Monografico: El reto del ciclismo urbano, texto 9: 147-165.

\title{
OBJETOS TIRADOS, OBJETOS SAGRADOS. Reapropiación tecnológica de la bicicleta
}

\author{
Carlos DIZ \\ Universidad da Coruña (España) \\ carlos.diz@udc.es
}

\section{WASTE OBJECTS, SACRED OBJECTS. Technological reappropriation of the bicycle}

Resumen: En este artículo describiré el funcionamiento de ReCiclos, un taller de reciclaje y autoreparación de bicicletas, ligado a la Masa Crítica. Analizaré las experiencias cicloactivistas y su relación con la ciudad. El taller funciona como una operación colectiva de reapropiación tecnológica, ejecutada en base a hackeos, aperturas y ensamblajes, con el objetivo último - dirán- de "llenar la ciudad de bicicletas". Frente a una ciudad orientada hacia el exterior, la bicicleta se presenta como un símbolo del cambio, capaz de oponer a ese movimiento centrífugo (hacia fuera) un movimiento centrípeto (hacia dentro), reconectando con el corazón de la metrópolis. Comprender el activismo bicicletero y repensar las relaciones entre tecnología, ciudad y política serán los objetivos principales.

Abstract: In this article, I will focus on the everyday life of ReCiclos, a recycling and self-repair bicycle workshop linked to the Critical Mass. I will analyse the activist experiences and its relationship with the city. The workshop functions as a collective operation of technological reappropriation, based on hacks, openings and assemblages, in order -as they say- to "fill the city with bicycles". Facing a city that today is oriented outwards, the bike is presented as a symbol of change, able to oppose to this centrifugal movement (outwards) a centripetal one (inwards), reconnecting with the heart of the metropolis. Understanding bicycle activism and rethink the relationships between technology, city and politics here will be the main objectives.

Palabras clave: Activismo. Bicicleta. Ciudad. Tecnología. Ensamblajes.

Activism. Bicycle. City. Technology. Assemblages 


\section{Introducción: Bicicletas viejas, Ciudades nuevas}

"Un puto infierno". Así define Tomás su entrada en furgoneta a la ciudad de A Coruña. La "furgo", tanto como el coche, le supone un incordio en términos de movilidad urbana. "Los coches no son sanos", dice. "Cuando voy en coche voy encapsulado. Me siento oprimido porque no soy dueño de mi movilidad". Atascado en la principal vía de acceso, la avenida de Alfonso Molina -en verdad una autovía urbana que discurre hasta el centro de la ciudad-, indica cómo los embotellamientos le producen un dolor en el cuerpo: "Son horas que me duelen. Cada hora que paso en un atasco me desgarro". La alegría de la bicicleta, para él, consiste también en hacer que el tiempo no duela.

Tomás forma parte de una vasta población flotante que entra y sale cada día de la ciudad, principalmente por razones laborales, sin habitar propiamente en ella. Cansado del apurado ritmo citadino, no hace mucho decidió mudarse a una pequeña parroquia en uno de los municipios colindantes, a $17 \mathrm{~km}$ de A Coruña. Estudió con detenimiento su traslado, para depender lo menos posible del automóvil: buenas combinaciones de autobús y a un tiro de piedra del apeadero del tren. Cada mañana de invierno, salvo excepciones, toma el bus cerca de casa. En la bodega carga su bicicleta, hermosa y vieja pieza a la que este fornido cuarentón guarda especial cariño, pues es la misma que utiliza desde los 14 años. Cuando se apea en la estación se sube y pedalea hasta su lugar de trabajo, en el centro; lo mismo a la vuelta. En verano vuelve a casa pedaleando.

Vasta población flotante de cuerpos metropolitanos. Cuerpos, como el de Tomás, que trazan día a día -en sus constantes idas y venidas, entrando y saliendo, circulando- rutas inherentes a la lógica metropolitana que define a la ciudad contemporánea, la misma que entremezcla y yuxtapone los binomios de lo rural y lo urbano. Viajes que ejemplifican el movimiento incesante, las fuertes dependencias, los intercambios continuos, las conexiones intensas, la localización en nuestro territorio de una lógica globalizada.

A través de lo que él mismo define como un "activismo de la bicicleta" y un "activismo de la movilidad", Tomás - uno de los pioneros de ReCiclos y de la Masa Crítica local- desea, en sus propias palabras, "hacer las ciudades más humanas". Para ello, la bici se le presenta como aliada: "el vehículo más humano". Más humano, dirá, por el ritmo que admite y despliega dentro de la urbe, y por su relativa proximidad con el caminante, o en este caso, con el peatón. Repensar la ciudad a través de las dos ruedas: he ahí el empeño de Tomás y de tantos compañeros y compañeras; entenderla como algo más que un vehículo, entenderla como un símbolo y un artefacto político. Para él, informático que empezó a pedalear en la ciudad para ir al trabajo y para hacer recados, y que al final -queriendo "ganar tiempo" y pasar de una media de $5 \mathrm{~km} / \mathrm{h}$ a pie a una de $15 \mathrm{~km} / \mathrm{h}$ pedaleando- terminó usándola a diario, la bicicleta tiene algo de sagrado. Dicha sacralidad, en su biografía, se le aparecía ya en sus primeros años de activismo con la Masa Crítica coruñesa, en su voluntad de contar y compartir las bondades de tal instrumento: "Es como leer un buen libro. Te gusta, descubres que tienes una máquina del tiempo en tus manos... y se lo quieres contar a alguien”. Un libro que leer pedaleando. En su "activismo apologético", tal y como él lo define con gracia, Tomás quería desde un principio contagiar y compartir su experiencia a pedales. En este sentido, la Masa Crítica funcionaba como punto de encuentro para convencer cada vez a más gente. Desde entonces, Tomás se ha entregado a la causa, en una entrega que asocia con la religión: "Me volví como uno de esos tipos de la Iglesia Evangélica que van repartiendo panfletos. Consideré que había que salvar al resto". La bicicleta se le presentaba, así, como un vehículo de salvación, como un objeto sagrado que todo el mundo debía conocer. 


\section{Giro de la movilidad}

Asistimos en nuestros días, golpeados por la crisis económica y también por la crisis climática, a un cambio de paradigma urgente y fundamental, el que va de la "transportación" a la "movilidad" (Mendoza, 2016), referida esta última ya no a la mera circulación de vehículos motorizados sino a un derecho de ciudadanía. Y es que la malograda "libertad de movimiento", coartada sistemáticamente por nuestros gobiernos en el campo de las migraciones o en el de los refugiados, por ejemplo, se reconoce y se ejerce al mismo tiempo en el plano de la ideología tanto como en el de la utopía, recogida y reconocida en las declaraciones de las Naciones Unidas y de la Unión Europea.

Existe un giro móvil, un "giro de la movilidad" (Tironi, 2015) que en las últimas décadas ha incentivado múltiples análisis de la vida social desde su carácter dinámico. Tales son las paradojas de un mundo que cuenta con la excepción del sedentarismo forzado; un mundo en el que, teóricamente, se puede hacer casi de todo sin moverse, pero en el que cada vez más población se desplaza. Los procesos de globalización nos trajeron las metáforas de un "mundo de flujos" (Appadurai, 2000), de personas, imágenes, objetos o tecnologías, no homogéneos sino asimétricos y disyuntivos. Sus aceleraciones, dislocaciones e intensificaciones han implicado una reorganización y un reordenamiento espacio-temporal, bien por la vía de una celeridad asociada a la "compresión" (Harvey, 2008), bien por la vía de una extensión asociada al "desanclaje" (Giddens, 1993).

En el ámbito de la ciudad, el giro móvil vino precedido desde la década de 1960 por un "giro espacial" (Soja, 2008), con el que se quería concienciar de las interrelaciones entre espacio, conocimiento y poder, politizando el saber urbano y replanteando las maneras de concebir la ciudad, entendida ahora en términos de conflicto, desorden y discontinuidad. He ahí, al compás de las revueltas -de los suburbios estadounidenses a los bulevares parisinos-, el despegue de una suerte de economía política urbana, basada en el análisis crítico de las desigualdades, los procesos de urbanización y la producción social del espacio en la ciudad (Castells, 2004. Harvey, 1979. Lefebvre, 2013).

A la hora de hablar del ciclismo urbano, este giro global se retraduce en un giro específico de la movilidad urbana, fundamental para repensar nuestra vida en la urbe y urgente en tanto que se agudiza conforme aumenta la crisis ecológica. Movilidad que habrá de entenderse, en el contexto de los juegos de reapropiación de la tecnología y de los espacios de la ciudad, como un "habitar móvil"; todo itinerario, todo recorrido, es al fin y al cabo una vivencia social del tiempo y del espacio, e implica una manera concreta de habitar y de producir la ciudad. No cabe entender el transporte como fenómeno aislado sino en relación con el contexto cultural, destacando su papel en el mantenimiento y reproducción del modelo territorial y del sistema urbano configurado a partir de él (Fernández Durán, 1980); tal es el caso de la prioridad dada desde mediados del siglo XX al transporte por carretera (de mercancías y personas), principalmente en automóvil, que ha obedecido a intereses económicos más que a patrones de eficiencia. Una prioridad ligada a los beneficios de las industrias petrolífera y automovilística, así como al carácter de desencadenador de consumo que tiene el coche, directamente (metal, caucho, vidrio, etc.), o indirectamente, al hacer viable elementos como la segunda residencia, aupada por el modelo infraestructural desarrollado en torno a la urbanización expansiva.

Así, ante un paisaje de "vidas móviles" desplegado en base a las formas rápidas de transporte -que afectan la vida ordinaria y que hacen que muchos de los desplazamientos se vuelvan insostenibles, dada la congestión del tráfico, las emisiones de $\mathrm{CO}_{2}$, etc.-, el paradigma de la movilidad (o de las movilidades) se antoja central al analizar los procesos de construcción y deconstrucción de la identidad contemporánea (Elliot; Urry, 2010). He ahí el Homo Mobilis (Amar, 2011), manifestación del nuevo paradigma, que pasa a concebir la movilidad ya no tanto (o ya no sólo) como la suma de viajes realizados sino como la vía para 
la creación de links o relaciones. Para los protagonistas de estas páginas, "cicloactivistas" o "activistas de la bicicleta", moverse en la ciudad cobra sentido en tanto refuerza la dimensión vivencial, en tanto revive el valor de experiencias, encuentros y descubrimientos. Ir más rápido y más lejos, valores insignia del progreso y la modernidad, dejan de ser las condiciones necesarias y suficientes para un desplazamiento urbano alternativo. Ahí aparece la "religancia", tal y como la define Amar (2011), esto es, como la combinación de relaciones y lazos, o de otro modo, la movilidad en tanto creadora de relaciones y el movimiento en tanto creador de lugares. Frente al "tiempo-distancia", dirá, un recorrido entre puntos fundamentado en la optimización y en el cálculo racional, el "tiempo-sustancia", basado en la humanización del tiempo y en la involucración de afectos en la travesía. El diseño urbano, las tecnologías de la información, la expansión de la conectividad y la diversificación de dispositivos están contribuyendo a disociar cada vez más las actividades de los lugares donde se llevan a cabo. Tal vez, sugiere el autor, no tardemos en evaluar un sistema de transporte del mismo modo que evaluamos hoy un sitio web, en función de los links y los contactos que estimula, en función de su valor red.

\section{$* * *$}

El velocípedo, en este sentido, se vuelve una tecnología privilegiada con la que repensar la ciudad contemporánea. Y es que, históricamente, las tecnologías y las ciudades han aparecido como construcciones sociales que se implican la una a la otra, y he ahí que tanto los imaginarios tecnológicos como los imaginarios urbanos interaccionen en los procesos de construcción de la ciudad y en los modos de vida que en ella se desarrollan (Vera, 2013). Véase, además, que la ciudad se ha adjetivado a lo largo del tiempo en base a su relación con el imaginario tecnológico dominante. Por citar sólo algunos casos, ahí está la "ciudad moderna", ligada al futuro, contando primero con el ferrocarril y luego con el automóvil como piezas clave (Williams, 2011); el tren unía diversas partes del territorio, enlazaba comunidades y difundía el uso del telégrafo y la unificación y coordinación horaria, mientras que el coche -la tecnología que más define la Modernidad Cinética (1900-1940) y que más ha afectado a los procesos urbanos- corría como máquina cultural y soporte del individualismo (Giucci, 2007). O más recientemente, con el auge de la globalización, la "ciudad informacional" (Castells, 1995), atravesada por tecnologías de la información y articulada en torno a flujos y lugares, o la "ciudad global" (Sassen, 1999), sostenida por el conocimiento, los transportes o las telecomunicaciones. Hoy vivimos envueltos en el discurso emergente de la smart city, la ciudad supuestamente "inteligente", también referida como "eficiente", basada en el manejo de infraestructuras de comunicación, transporte y energía, enfatizando los sistemas de robótica y las redes de sensores para la gestión del territorio, y desplegando a su vez dispositivos de control y vigilancia (Sadowski; Pasquale, 2015).

Podría decirse, en base a la relación entretejida entre el cuerpo, el biciclo y el espacio urbano, entre la ciudad y la tecnología, que esta última -en toda su polisemia y en toda su diversidad- supone en gran medida una manera de ordenar el mundo (Winner, 1980). Un ordenamiento continuo, nunca acabado, siempre en conflicto. Bien es cierto que la elección entre tecnologías influencia el modo en que nos relacionamos, nos comunicamos, consumimos, habitamos o nos transportamos. Por ello, cada innovación tecnológica debería ser comparada con las normas y con las reglas que rigen nuestra vida en común, pues -al fin y al cabo- nuestros comportamientos no vendrán mediados sólo por leyes, sino también por cables, puentes, carreteras, vehículos, teléfonos o conexiones.

En este sentido, la clásica distinción establecida por Mumford (2006), quien diferenciaba entre "técnicas autoritarias" y "técnicas democráticas", todavía es útil para repensar, a través de las prácticas, los discursos y las narraciones de nuestros informantes, las relaciones entre las tecnologías y las ciudades, en este caso a través de las frecuentes reflexiones 
críticas surgidas en torno al automóvil y a la bici en términos de transporte urbano. Espacios y artefactos que son reapropiados, pero también diseñados, políticamente. Sólo basta con acudir a un par de ejemplos históricos. Véanse los amplios bulevares parisinos abiertos por Haussmann a mediados del siglo XIX, paradigma urbanístico de control social, estirando y ensanchando el espacio urbano para facilitar el control policial y los desfiles militares, impidiendo el levantamiento de barricadas; o véase la remodelación de las ciudades estadounidenses tras los disturbios de la década de 1960, creando fronteras físicas (autopistas) que eran a la vez morales, separando entre sí distintos barrios y distintos grupos de población. Fue el propio Robert Moses, principal artífice del urbanismo expansivo de la ciudad norteamericana en la primera mitad del siglo XX, quien limitó -por ejemplo en Long Island (Nueva York) - la altura de los pasos elevados en los puentes de las autopistas. Al bajar la altura de los pasos restringía conscientemente el acceso de los autobuses, el único transporte público que tomaban las clases bajas (y negras), que sin disponer de vehículo privado se veían impedidas de acceder a las playas del lugar, a las que sí acudían en sus utilitarios las clases medias (y blancas). Sin duda, los "movimientos de vida independiente" organizados en torno a las necesidades de la población con diversidad funcional, expandidos desde los años setenta, mucho tienen aún que enseñarnos en torno a estas cuestiones materiales e infraestructurales, que son al mismo tiempo cuestiones urbanas, políticas y tecnológicas.

\section{Etnografía ambulatoria}

Este artículo es producto de una etnografía ambulatoria, escrita entre la cuartilla y los pedales, rodando a través de la ciudad. Entre septiembre de 2010 y julio de 2012 desarrollé lo que Marcus (2001) denominó "etnografía multilocal” o "trabajo de campo multisituado", desplegado entre activistas de la bicicleta para atender a la circulación de tramas, símbolos, artefactos e identidades políticas, en este caso siguiendo a los cuerpos y a los objetos a través de las calles y, en ocasiones, entre países. Dada la actualidad y la relevancia del ciclismo urbano en las ciudades europeas, decidí profundizar las relaciones entre el cuerpo y la ciudad, mediadas en este caso por un concreto artefacto cultural, la bicicleta. Para ello, mi metodología se basó principalmente en la observación participante, conviviendo con los protagonistas, y en el desarrollo de entrevistas en profundidad. Además, pedaleando como uno más, el análisis de sus vidas rodantes se combinó con pinceladas de autoetnografía y observación interior, poniendo mi cuerpo en la narración.

En estas páginas mi atención se centrará en ReCiclos, taller autogestionado de reciclaje y auto-reparación de bicis, ligado a la Masa Crítica de A Coruña. El taller funciona como una operación colectiva de reapropiación tecnológica, ejecutada en base a hackeos, aperturas y ensamblajes, con el objeto último - dirán- de "llenar la ciudad de bicicletas". Una ciudad orientada hoy hacia el exterior, difuminada, y frente a la cual, pese a su aparente fragilidad, tal vehículo se presenta como un símbolo del cambio, capaz de oponer a ese movimiento centrífugo (hacia fuera) un movimiento centrípeto (hacia dentro), operándose un recentramiento y una reconexión con el corazón de la ciudad.

Rearmadas y puestas a punto, las bicicletas viejas y abandonadas renacen y vuelven a rodar, dándose la transición de "objetos tirados" a "objetos sagrados". En su pedaleo, los protagonistas reivindicarán ciudades nuevas o, más bien, diferentes. Y es que, al menos en las dos últimas décadas, el "cicloactivismo" se ha extendido rápidamente por todo el mundo, defendiendo el derecho a la movilidad como una cuestión inseparable del derecho a la ciudad. Calmando el tráfico, pausando el ritmo, interactuando con el entorno y convirtiendo el vehículo en un símbolo rodante y ecológico, de salud, eficiencia y sostenibilidad, los cicloactivistas politizan la bicicleta y nos ayudan a repensar la ciudad. 


\section{ReCiclos: la casa de las cosas, el tiempo de los Objetos}

"Darle una segunda oportunidad a los objetos". Ese parecía ser, como recuerda Tomás y como figura en uno de los primeros panfletos del taller, uno de los principales objetivos. ReCiclos vio la luz en el seno del Centro Social Própolis en diciembre de 2008, aunque se constituyó desde el inicio como un proyecto alojado, con su propia asamblea. A algunos "maseros", pedaleantes en la Masa Crítica, activa en la ciudad desde el 2005, se les propuso ocupar el espacio con su proyecto bicicletero. Cuando las gentes del centro social finiquitaron su proyecto en 2010, el taller siguió adelante exitosamente, ocupando dos sótanos de una vieja librería. Se inspiraba parcialmente en el proyecto coruñés "Bici-Solidaria", impulsado en 2004 por varias asociaciones que recogían y regalaban bicicletas, tal y como hacían desde hacía décadas los activistas estadounidenses de Bikes Not Bombs, enviándolas a zonas pobres de Nicaragua. Se inspiraba también en los talleres autogestionados que desde hace al menos 15 años han aparecido en Europa (Lorenzi, 2010): el del Patio Maravillas en Madrid o el de Bicios@s en Barcelona, entre otros, pero también los atéliers franceses, las ciclo-officinas italianas o las bike-kitchen diseminadas por Inglaterra, Austria o Alemania. ReCiclos era un gesto más en un mar de movimientos.

Un gesto que, tanto en el ensamblado y montaje de los "proyectos de bici" como en la acción recicladora, funcionaba según Tomás como un puzle: "ese puzle que sólo necesitaba que se juntaran las piezas". Puzle humano, político y cultural, también maquínico, compuesto a partir de restos y desechos, de material sobrante, de olvidos, con múltiples manos y en consonancia con los regímenes de excedencia que gobiernan nuestra contemporaneidad (De Giorgi, 2006). Un puzle hecho a partir de máquinas viejas, abandonadas, "recuperadas" de meses de desamparo en las calles, arrojadas a la lluvia y al frío, amarradas a farolas y a señales. Recicladas de esquinas y contenedores de basura. Partes usadas (a veces nuevas), cedidas y recogidas en las tiendas de la ciudad. Olvidadas en trasteros, oxidadas en garajes, cubiertas por el polvo del invierno. Traídas por vecinos, desconocidos, amigos o activistas. Biciclos de cualquiera, llegados desde cualquier lugar, para cualquiera. Como en Broken Bicycles, la canción de Tom Waits que Tomás sentía como un himno del taller: "Bicis rotas, viejas cadenas rotas, manillares oxidados bajo la lluvia... Alguien debería tener un orfanato para todas estas cosas que ya nadie quiere". ReCiclos no era un orfanato, pero tampoco un cementerio. Si bien el sótano era una metáfora de la sociedad de consumo, de los ciclos de producción y de era de la obsolescencia, en el taller se operaba cada tarde de lunes una suerte de magia blanca y colectiva, que en base a "mecaniquear", "trastear" y "cacharrear" insuflaba vida en materia muerta. "Darle una segunda oportunidad a los objetos" significaba, en efecto, reintroducirlos en el ciclo, devolverlos a la calle, hacerlos rodar como un día rodaron.

El taller, y con él los dos bajos de la tienda, funcionaban como una "casa de las cosas" (Bachelard, 2000). Cajones, estantes, cajas, armarios, trastos, piezas, cacharros, cachivaches. Allí olía a grasa, caucho y goma, a neumático. Al descender al "menos uno" sonaban varios acentos: gallego, cubano, peruano, senegalés, dominicano. Sin guantes en las manos, pronto te manchabas y emborronabas. Mejor usar ropa vieja, como los monos o mandiles allí dispuestos. Entre el clic-clac y el golpeteo de herramientas, una rueda silba en el aire antes de ser radiada. Alguien comprueba los cambios, con la bici aupada y sujeta por un pie de reparación, mientras gira los pedales con la mano. En un barreño se hunde una cámara para detectar un pinchazo. Estanterías recicladas almacenan cientos de piezas, cada cajón con su etiqueta: piñones, catalinas, tijas, sillines, cadenas, arandelas, cables, luces, timbres, radios, bujes. En el "menos dos", a un lado de la pared central se apilan las bicis, al otro se amontonan más cadenas, algunos portabultos y, agolpadas en el suelo o colgadas en la pared, cámaras, llantas y cubiertas. Casi tantos criterios de clasificación como objetos mismos: forma, tamaño, edad, origen, valor, materia, estado (o salud), etc. 


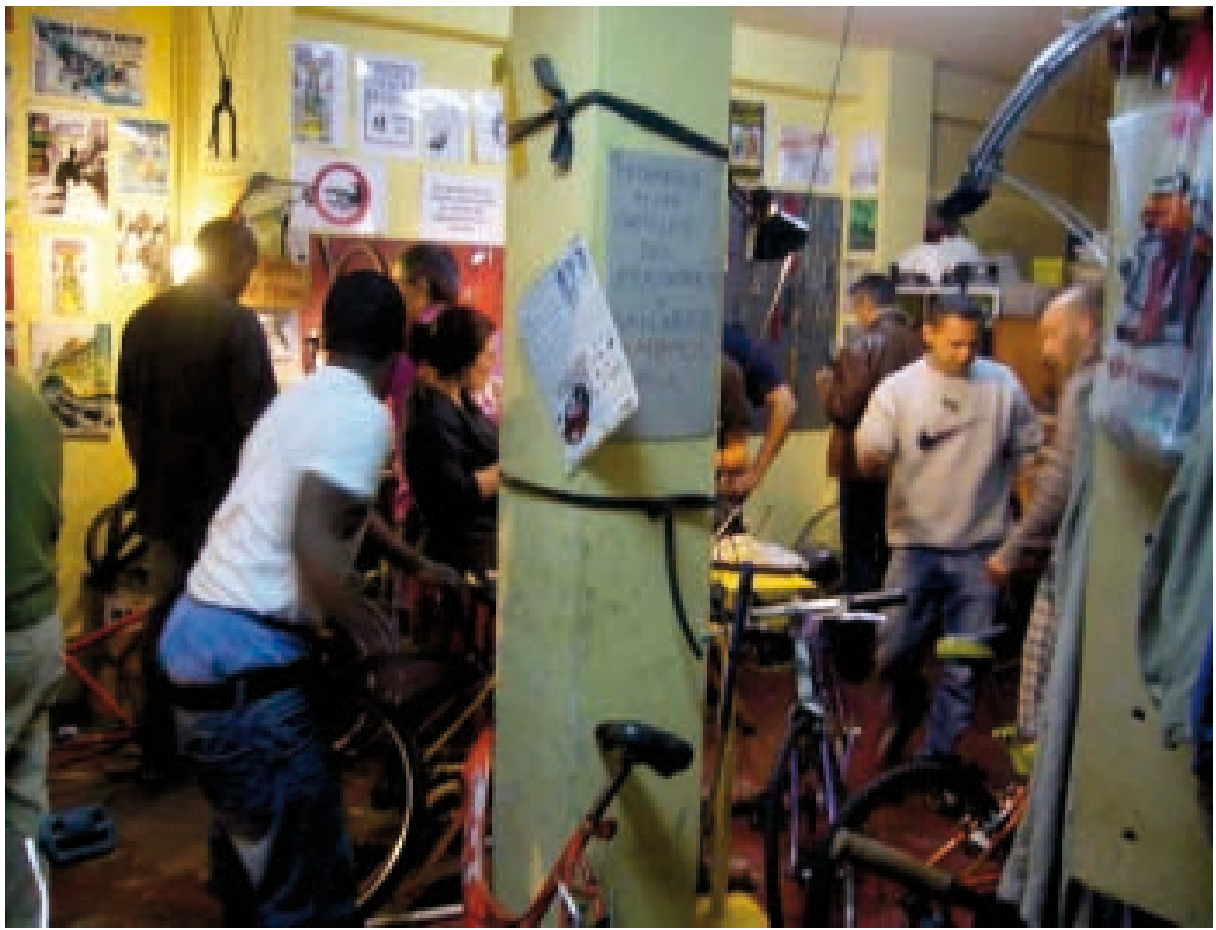

Figura 1. ReCiclos. Menos Uno.

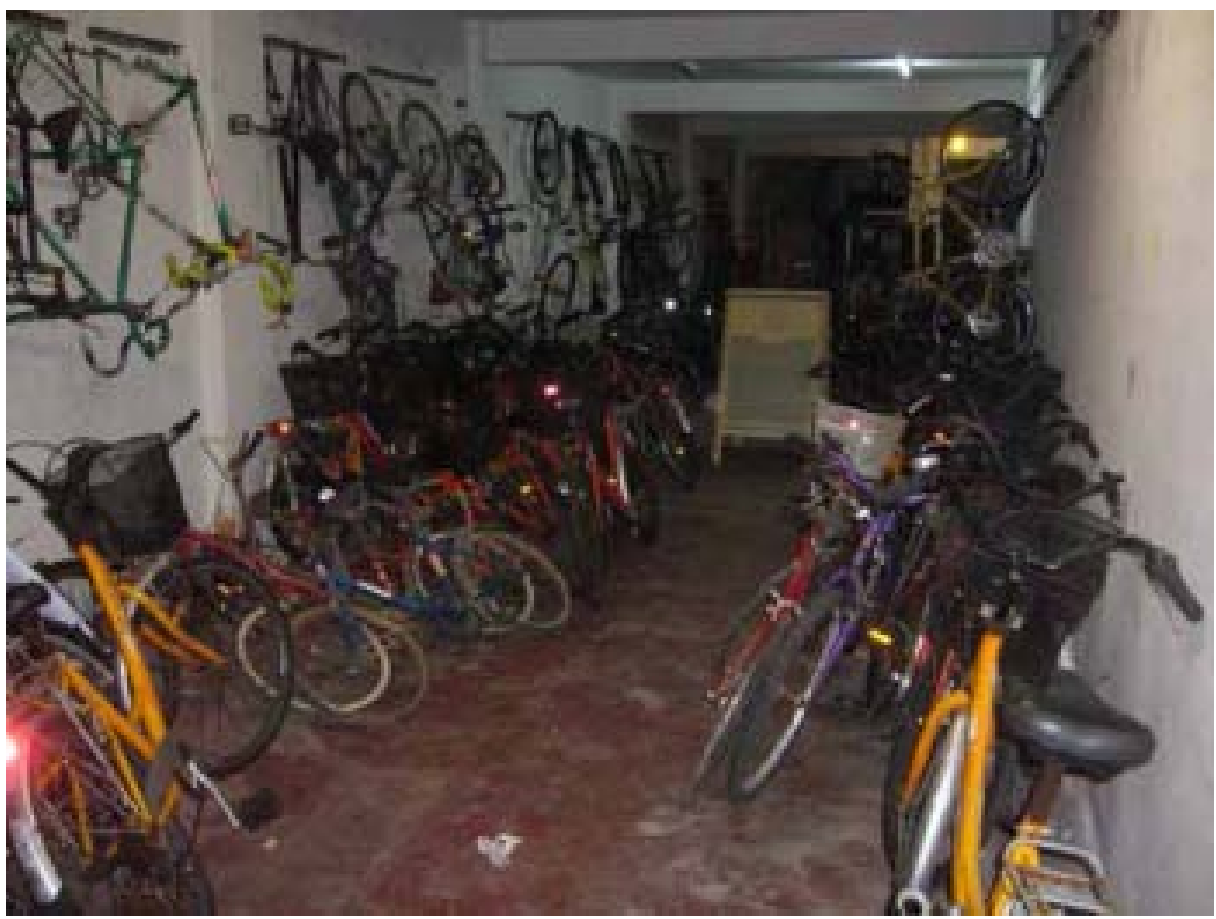

Figura 2. ReCiclos. Menos Uno. 
Definitivamente, la casa de las cosas está marcada por el tiempo de los objetos, por su omnipresencia: "Vivimos el tiempo de los objetos. Y con esto quiero decir que vivimos a su ritmo y según su incesante sucesión. Hoy somos nosotros quienes los vemos nacer, cumplir su función y morir" (Baudrillard, 2012: 3). Hasta no hace mucho eran ellos quienes nos sobrevivían. ¡Bienvenid@s a la era de la obsolescencia! Bienvenidas y bienvenidos al mundo-chisme. Para mí, hacer trabajo de campo en un taller de mecánica equivalía muchas veces a quedarme sin palabras. No por asombro o estupefacción, sino por insuficiencia técnica y conceptual. He ahí la continua alusión al "chisme", minimizada conforme pasaban los meses y ganabas palabras, pues dejarse trabajar por el campo equivalía a ganar un lenguaje.El chisme es el término indeterminado de lo que no tiene nombre o no se sabe nombrar, y que no obstante funciona (Baudrillard, 1995).

Estos vehículos son mercancías que circulan a través de relaciones político-económicas transnacionales, ensambladas en sitios diversos, sujetas a proveedores, distribuidores y consumidores ubicados en regiones distintas y distantes. Por ello, y por los juegos de reapropiación a los que se somete, es un "símbolo flexible" y un "objeto multidimensional" (Vivanco, 2013), un objeto que circula. Tanto mi bici como las de Julio, Primo, Toño, Lois u Olivia -la proporción era eminentemente masculina-, tanto las de los "mecánicos" como las de los "usuarios", tienen y contienen "vidas sociales" (Appadurai, 1986). Si bien es cierto que se les otorga valor y significado, no es menos cierto que su circulación alumbra y perfila su contexto social. También ellas tienen sus "historias de vida" y su "biografía cultural" (Kopytoff, 1986): diseñadas, fabricadas, vendidas, usadas, desechadas, recicladas, pero siempre a merced de la acción humana. Véase el caso de Julio, quien rodó casi toda su vida en la bici de su hermano Lucio, como si el vehículo compartido materializase el estrecho vínculo que los une. $\mathrm{O}$ véase a Toño, que gastó su primer sueldo de socorrista (en pesetas) en una bici que le robaron la víspera de Nochebuena de 2004, tras "pasar la noche fuera"; a ella la cuidaba con esmero, y en sus primeros años -por miedo al óxido- sólo la sacaba cuando no llovía, aunque al final la acabaría sacando todos los días... desde el verano de 1985. Un movimiento de personas que discurre a la par de esta movilidad artefáctica. $\mathrm{He}$ ahí la vida en tránsito de bienes y objetos, y he ahí el viaje de sus valores, pues éstos poseen una cualidad móvil igual que la de los bienes, existiendo un significado en tránsito de los objetos (McCracken, 1986).

Objetos tirados, luego recuperados, reparados y regalados. He ahí las tres "R" que marcaban la hoja de ruta inicial: recuperar, reparar y regalar. "Esos objetos hacen que actuemos. Nos modifican. Están ahí y te los acabas encontrando". En estas palabras de Tomás resuenan las líneas trazadas por Latour (2008) en su teoría del actor-red, así como uno de sus principales deseos: "llenar de cosas la política" (Latour; Gagliardi, 2008). Teoría pertinente para el análisis tecnopolítico de estos procesos, para plantear la interagencia, problematizando la distinción "sujeto-objeto". Y pertinente, sobre todo, a la hora de reconocer la participación de los objetos en el curso de acción y al advertir la artificialidad de la división entre lo social y lo material. Válida para reconocer que cualquier cosa que modifica con su incidencia un estado de cosas es un actor (o un actante), y que "un actor es aquello que muchos otros hacen actuar" (Latour, 2008: 73), es decir, que vive envuelto y desenvuelto en una red. Así la bicicleta, en el día a día de estas gentes, se vuelve un actante que a su modo "hace hacer", que facilita -por ejemplo- experimentar la ciudad de un modo distinto a la manera en que un coche te la hace vivir.

\section{Abriendo la tecnología: búsqueda, hackeo y reensamblaje}

Más de una vez pude escuchar la siguiente frase: "Non damos bicicletas, damos mobilidade". Desde este enfoque, el derecho a la ciudad, definido en origen como "el derecho de los ciudadanos a figurar en todas las redes y circuitos de comunicación, información e 
intercambios" (Lefebvre, 1976: I, 19), pasaba primero por un derecho a la movilidad. Y si ésta, como ya dije, debería ser pensada como un habitar móvil, cabe recordar que -en gran medida- habitar significa "tener acceso" (Sloterdijk, 2006), y que el acceso es uno de los mantras recurrentes entre los defensores de las dos ruedas. En este sentido, pese a sus frecuentes críticas a los paradigmas de la modernidad -la velocidad, el progreso, etc.-, los activistas hacían hincapié en la urgencia y el derecho a moverse, reproduciendo quizá sin saberlo una lógica moderna, aquella por la cual -históricamente- progreso y movilidad se han retroalimentado; ya en un primer momento esta última implicó tener a dónde ir, no sólo en términos espaciales sino también estructurales, anhelando moverse entre clases. No obstante, en el ciclotaller se reclamaba otra movilidad, inclusiva y sostenible. Si la antropología clásica nos ha enseñado que la pobreza no se define objetivamente, que no es tanto una pequeña cantidad de cosas cuanto una relación social entre personas, entre medios y fines, también los recientes estudios urbanos demuestran que puede ser medida en relación con el acceso a la movilidad, dado que ésta no se distribuye de modo igualitario entre la población (Graham; Simon, 2001).

Cada tarde de lunes, ReCiclos funcionaba como un experimento tecnosocial. Por orden de llegada, por sorteo, varias eran las metodologías de acogida y de organización desplegadas para recibir y acompañar a los "usuarios". En verano, cuando la lluvia cesaba y era mayor la afluencia, era común que los "mecánicos" se viesen desbordados, pues sólo cuatro o cinco conformaban el grupo central, junto a dos o tres "satélites" que entraban y salían de la rutina semanal. ¿Quién venía al taller? Mucho activista, mucho migrante, mucho currante, mucho migrante currante, poco migrante activista. Entre los mecánicos, casi todos en la treintena o en la cuarentena, dominaban varones de clase media, unos con trabajo y otros en situaciones de precariedad. Entre los usuarios, jóvenes y gente de clase trabajadora. Pero he ahí uno de los desafíos, liquidar las fronteras entre "mecánicos" y "usuarios", superar la caridad a través del empoderamiento. De ahí su insistencia al decir: "No somos una ONG". Superar el asistencialismo por la vía del Do-It-Yourself, o cuanto menos, del Do-It-With-Others. Para purificar el espacio, exorcizar el capital y potenciar el valor de uso manifestaban una "alergia" al dinero, prohibiendo toda transacción económica en el taller y disponiendo un bote a voluntad de cada uno.

En ReCiclos predominaba el material más viejo, nada de frenos hidráulicos y pocas suspensiones, mucho hierro y aluminio y nada de titanio, ni fibra de vidrio ni carbono. Pero antes, tal maniobra de reapropiación ha de ser contextualizada. Por un lado, una serie de cambios tecnológicos, políticos y culturales -así como una suerte de transición mitológica, que ha situado a las dos ruedas en un horizonte verde y ecológico, y al cuerpo como lugar de saludhan llevado, sobre todo desde la década de 1990, a un revival en ámbitos como el deporte o el transporte urbano. El boom de la mountain bike, por ejemplo, más segura y con componentes más resistentes, con un mejorado sistema de frenado, más equilibrio que la bici de carretera y la bendición de las marchas bajas, fue clave en tal resurgimiento, al convertirse en un artefacto popular. Por otro lado, en los márgenes de la industria y entendiendo que hay algo en este vehículo que lo vuelve maleable y reapropiable -que es una tecnología bastante simple, movida por el cuerpo y compuesta por un engranaje sencillo, aunque anudada en un complejo conjunto sociotécnico-, viene consolidándose en las últimas décadas una subcultura urbana que desafía algunos de los usos, valores y diseños de la cultura ciclista oficial (Rosen, 2002). Al interior de la industria, por ejemplo, el caso de la multinacional japonesa Shimano ejemplifica ciertos cambios. Punto de pasaje obligado para fabricantes, minoristas y consumidores, representa hoy el paradigma de las mutaciones en las praxis de producción y organización. Desde la década de 1970, absorbidas buena parte de las fábricas europeas, los principales exportadores de biciclos han sido los países del Asia Oriental. Dentro de un proceso global de flexibilización, se han flexibilizado también los métodos de fabricación, montaje y corte (de tubos y cuadros, por ejemplo), multiplicando los diseños. Las tareas 
repetitivas han sido sustituidas por el láser y la robótica, y cada vez un mayor número de productos - de cara a una maximización de beneficios- son diseñados en torno a la obsolescencia programada, lo que complejiza las opciones de maleabilidad y reapropiación tecnológica, pues si un componente falla, o bien requerirá de un experto para su reparación o bien será desechado y rápidamente reemplazado. Una complejización que no sólo incide en proyectos autogestionados como ReCiclos, de carácter alternativo, sino en el resto de empresas del mercado, afectadas por tal diseño opaco y obsolescente, y atentas a las constantes innovaciones que Shimano introduce.

Fuera de la industria, y contestándola desde los márgenes, proyectos cicloactivistas empapados en la retórica del "Hazlo-tú-mismo" y focalizados en el transporte urbano han venido creando "nuevas narrativas de la tecnología" (Furness, 2006), enfatizando el empoderamiento y manifestando su voluntad de participar activamente en los procesos tecnológicos y en la toma de decisiones respecto a la tecnología. Lo mismo había ocurrido, por ejemplo, con el denominado home-power movement -iniciado en la década de 1970-, que en su búsqueda de la "democratización tecnológica" ofrecía una alternativa a través de la generación de energía eléctrica en el hogar, vía sistemas fotovoltaicos. Un movimiento ecologista que se preguntaba cómo y quién decidía el diseño de los artefactos, cuestionando el binomio "expertos-usuarios" y ofreciendo a los consumidores la posibilidad de diseñar, instalar y mantener sus propios sistemas de energía.

En el campo cicloactivista, la bici ha sido vista no sólo como un vehículo sino como una parte de un entramado sociotecnológico mucho mayor, capaz de transportar mensajes e ideologías. Así, si ciertas tecnologías representan para algunos una amenaza (al medio ambiente, a la seguridad o a determinados intereses particulares), otros -en cambio- seleccionan cuáles de ellas son compatibles con sus valores, creencias o modos de vida (Douglas, 1998). Según Tomás, por ejemplo, existe una doble dirección: "ideologías que te llevan a la bicicleta y la bicicleta que te lleva a ciertas ideologías". Para mis informantes, en la ciudad -y siempre pensada en su relación antitética con el coche- ella representa una tecnología válida para la democracia y buena para pensar el cambio social. Entendida como "materialidad verde" y "materialidad ordinaria" (Horton, 2006; 2009), es a un tiempo simbólica (objeto icónico del discurso político) y práctica (objeto de uso diario). Materialidad sencilla, pero que tiene mucha importancia en la producción de identidades políticas, al igual que para otra gente la tienen artefactos como los paneles solares o los molinos de viento. Una cultura material con la que los activistas la convierten en un vehículo de oposición (y de salvación), comunicando con ella una particular visión del mundo, valores e ideas que aparentemente no tendrían cabida en otras materialidades. Esto es, la bicicleta es favorecida al entenderse que no encajaría en el tipo de mundo al que se le contrapone, y que no obstante necesita como fuente de identidad alterna.

\section{De mecánicos a montadores: marketing, obsolescencia y complejización}

Luego de buscar materiales en el exterior llega la búsqueda puertas adentro, entre el mar de piezas, restos y desperdicios. Es común que los que llegan sin bici tengan que hacerse una por piezas. Tijas, horquillas, ruedas, manetas de frenos, cambios... También la búsqueda de herramientas, de las comunes a las específicas: tronchacadenas, llaves de cazoletas fijas, extractor de piñones para bujes de rosca, llave de tetones. Lenguaje técnico con el que uno se familiariza. Lenguaje que hibrida y se contagia, con expresiones que viajan entre mares y cuerpos - porque también migran los conceptos, también viajan las palabras-, otorgándole al taller una rica multivocalidad: cables de freno que serán "culebras" para los cubanos; la "coraza" en lugar de la cubierta, para los mexicanos; el "canasto" en vez de la cesta, para los dominicanos; y también el "manubrio", el "timón" o el "guiador", para el manillar; "tibar" para tensar; "punchar" y no pinchar; "espiga" en lugar de tija; "tripa" para 
referirse a la cámara; la "chicharra" para la piñonera; o los rieles del sillín, la "cebolla". Con uno u otro acento, hacerse una bici por piezas significa componer y recomponer a partir de fragmentos (mecánicos, lingüísticos), a la manera del bricoleur (Lévi-Strauss, 1992) -resignificando y recombinando piezas y mecanismos-, e implica servirse de objetos, ya no de mercancías, pues entiendo éstas no como un tipo particular de productos sino como una fase en la vida de los mismos (Appadurai, 1986).

Entre nuestros protagonistas, del mayor al más joven, estos cambios a gran escala repercuten en sus pequeñas maniobras en el día a día del ciclotaller. Toño, que a sus 50 años pedalea a diario, entre ida y vuelta, los cerca de $10 \mathrm{~km}$ que separan su piso alquilado del hospital público donde trabaja de celador, es quien tiene más experiencia. Fue uno de los primeros en usar la bici en la ciudad, pues el resto -como él dice- o se iban "de machacas de fin de semana" (a machacarse el cuerpo en la carretera), o bien la utilizaban para ir al parque, pues en aquella época (en el año 1985) aún no había llegado a Coruña la revolucionaria mountain bike. Él se queja del "puro marketing" de las compañías:

"Lo que hacen los fabricantes es vender todo el rato cosas 'nuevas', nuevas entre comillas, porque son muy parecidas a las que ya había. Hay una competencia tan feroz por sacar cosas nuevas que van sofisticando piezas que funcionaban perfectamente. Ahora hay cambios electrónicos, frenos de disco hidráulicos que hace falta cuidarlos con un aceite especial... Los frenos V-Brake, por ejemplo [Frenos de llanta, de los más habituales], no frenan igual, pero si no compites o si no vas por el monte te valen para un uso normal".

A esta crítica al marketing la acompaña una reflexión sobre la complejización. Según Lois, el mecánico más joven, el único veinteañero, que aprendió en el seno de ReCiclos y hoy ha dado el salto al mundo laboral con una cooperativa de ciclomensajería, basada en el "transporte ecológico" y la "economía social”, existe una tensión:

"Por un lado, cada vez é máis opaco, son tecnoloxías menos abertas. Polo outro, na sección de mecánica de revistas comerciais promociónase o 'faino ti mesmo'. Dunha banda a tecnoloxía é sobrecomplexizada, con materiais de usar e tirar, e doutra banda hai unha interese crecente por abrir cada vez máis a tecnoloxía, compartindo titoriais na Internet ou vídeos no YouTube".

Un discurso ambiguo, pues, entre los fabricantes, y entre los activistas un aguzado deseo de abrir la tecnología. Marketing, obsolescencia, complejización... y también añoranza, una suerte de memoria técnica: "Antes se reparaba máis e se daba valor aos compoñentes que duraban", continúa Lois. "Eu teño unha bicicleta que ten 25 anos e ten aínda os compoñentes orixinais. ¡É inimaxinable que un compoñente de hoxe, dentro de 25 anos, vaia estar en bo estado!". Estos cambios, que afectan tanto a la producción como a la venta y al consumo, producen -según mis informantes- una singular transición: el paso de la era de los "mecánicos" a la era de los "montadores", en la que resulta más fácil, más rápido y más económico tirar piezas que hacer que funcionen.

Una vez en el taller, dicha transición -humildemente- trataba de ser revertida. Las máquinas se almacenaban en el "menos dos", siendo reutilizadas enteras o por partes, según su estado. El material se miraba con calma, se ordenaba, limpiaba, desmontaba o desguazaba. El sótano, especialmente los dos tableros de trabajo - uno por planta- funcionaba como mesa de operaciones; allí se efectuaba un análisis, se construía un diagnóstico y se daba un parte. Además de "las baratas", las que habían sido compradas en grandes superficies comerciales -fáciles de estropear y difíciles de ajustar-, en ocasiones también aparecían "reliquias", viejas máquinas o partes de máquinas de gran calidad y de hace más de 30 
años, con sólidos componentes fabricados à l'ancienne, y en cuyo tráfico -como cualquier reliquia- iban transformando poco a poco el espacio profano en espacio sagrado (Velasco, 2010). Un tránsito, dicho sea de paso, que llegaba a demorarse en ocasiones, fruto de un amor o de un fetichismo que llevaba a alguno de los mecánicos a conservarlas bajo tierra más tiempo del acostumbrado; sacrosantas reliquias que eran, con cierto paralelismo con la circulación contemporánea de órganos y tejidos, como fragmentos corporales que se reinstalaban en otros cuerpos, en otras bicis.

\section{Temporalidades y materialidades de lo político}

Cada "proyecto de bici" iniciado era la yuxtaposición de un proyecto individual -el de cada usuario- y de un proyecto más amplio, el de los mecánicos que sostenían el taller con su esfuerzo semana tras semana, con una simple y enorme intención política: ganar la ciudad para las bicicletas. Hacerse una bici por piezas suponía trabajar con fragmentos, mas también reensamblarlos, desplazándolos de una máquina a otra, de un cuerpo a otro. Tallas, gustos, colores, diseños, "tuneos" y "customizaciones", y desde luego la voluntad, la necesidad, el deseo, el desparpajo, la urgencia y la subjetividad de cada uno jugaban su papel en el proceso de singularización del vehículo. Un proceso íntimo de reapropiación, denso y polisémico, que cada cual vivía a su modo y que podía llevar más o menos tiempo, iniciándose a base de encajar, acoplar y reensamblar partes y piezas que ya antes -en otro lugar, por otras manos- habían sido ensambladas. Proceso que culminaba, en ocasiones, con el "bautizo" o la dación de nombres: para algunos, el vehículo era su "burra", su "bus" o su "caballo", para otros "Libertad" o "Rocinante".

Antes de sacarlas del subsuelo, devueltas a la calle cual reemergencia a la vida, se procedía con la última etapa del ritual: se le encolaba en el cuadro la pegatina de "un coche menos", convirtiendo la máquina en un mensaje rodante que permitía identificar al ciclousuario como "uno de los nuestros". A menudo se le instalaba una "bicimatrícula" con el lema No Oil, un CD usado compuesto a base de policarbonato, un derivado del petróleo, que se amarraba con bridas a los rieles del sillín. Eslogan ecologista que actuaba como pantalla proyectada sobre transeúntes y automovilistas, funcionando como boicoteo y acción propositiva, una invitación a moverse sin consumir combustibles fósiles.

Según la interpretación de Lois, cuya relación con las dos ruedas puede definirse bajo el arco de la "tecnopolítica" y la "tecnosocialidad" (Escobar, 2005), la reapropiación orquestada en ReCiclos tenía mucho de hackeo. Un hackeo ligado con la apertura y el open access. No se refería sólo a la informática, a las horas pasadas frente al ordenador rastreando webs e "infos", leyendo, traduciendo y compartiendo textos, tutoriales y manuales de reciclaje o de soldadura de cargo-bikes o de tall-bikes, o a la vasta colección de "entradas", "posts" y discusiones entabladas en el foro virtual de las Masas Críticas gallegas, un foro que revelaba cuán importante es en este campo -y cada vez en más campos- la tecnología para el sentido del "yo", funcionando como "modelo organizativo" y "zona de observatorio", y siendo capaz -al igual que los blogs- de acumular y orientar expectativas y esperanzas, labrando a su vez "identidades técnicas" (Estalella 2012).

Además, el hackeo se vinculaba -dentro y fuera del ciberespacio, tecleando en foros y mecaniqueando en ReCiclos- con un activismo tecnosocial organizado reticularmente, basado en la construcción colectiva de saberes, en la circulación libre de la información, en el código abierto, en la práctica descentralizada, en la conectividad y en la "lógica cultural de enredar" (Juris, 2008). Se basaba en la voluntad de abrir y de malear la tecnología. Por un lado, Lois se refería al taller como una "escola de aprendizaxe":

"Por un lado está a parte divulgativa, a promoción da bici como medio de transporte. Ensinarlle á xente a facerse as súas cousas e aprender nós mesmos 
a reparar, como algo estratéxico e importante, porque aumenta a confianza da xente [...] Por outro lado a bici é unha tecnoloxía fácil de abrir e modificar, facilmente prototipable. Fácil de apropiar, accesible".

He ahí la "ética hacker" (Himanen, 2002), popularizada a partir de los hackers, programadores apasionados que creen que es un deber compartir la información y elaborar software gratuito. Entusiastas de cualquier tipo que pueden dedicarse o no a la informática, y cuya actividad se basa en el despliegue de una moral alternativa, en la creatividad, la pasión y el placer, en la búsqueda de un valor social en sus tareas y en la difusión pública de sus resultados. En ReCiclos, tal hackeo se manifestaba abriendo piezas o destripando bicis. Pero además de abrir la tecnología se abría el espacio, se abrían los canales de acceso, participación, información y conocimiento: intercambiando herramientas y manuales, subiendo artículos y noticias al foro, compartiendo el visionado de tutoriales en Internet -en el propio taller, en un viejo ordenador al que se le instaló software libre-, comentando las experiencias de otros ciclotalleres y centros sociales, o impartiendo charlas. El taller, en un doble sentido, funcionaba como caja de herramientas.

Pero en ReCiclos no sólo se ensamblaban piezas. Se ensamblaban en primer lugar temporalidades. Cada nuevo proyecto era producto de un ensamblaje temporal en el que se fundían las disponibilidades, las presencias, las ausencias y los tiempos de vida de cada uno, así como el propio tiempo de los objetos: alguien salía montado en un sillín de hacía 10 años, con un cuadro de hacía 20, haciendo girar unas ruedas desechadas tres años antes. Se ensamblaban además toda una serie de trucos, técnicas y maneras de hacer, las cuales cambiaban entre mecánicos y usuarios, y según la procedencia de cada cual. Como decía Primo, joven dominicano criado dentro del ambiente de los talleres familiares: "Hacemos lo mismo... pero diferente". De esa amalgama de rutas, experiencias y saberes surgía un reensamblaje sociotécnico y cultural, hecho de materias, historias, acentos y memorias.

Se trataba no sólo de juntar piezas sino también trayectorias, gentes y relaciones. Ensamblar y reensamblar, e incluso desensamblar (por ejemplo los prejuicios existentes). En ReCiclos, cada persona, cada pieza -nunca isotópica, ni sincrónica, ni sinóptica, ni homogénea- era un actor en un conjunto, en una vasta red. Ahí radica la idea del actor-red, el blanco móvil de una cantidad de entidades que convergen hacia él. Desde esta mirada situada, los objetos moradores de esta casa de las cosas no determinaban la acción, pero tampoco eran sólo su telón de fondo: "Las cosas podrían autorizar, permitir, dar los recursos, alentar, sugerir, influir, bloquear, hacer posible, prohibir" (Latour, 2008: 107). Asistíamos a una dimensión material de lo político, a la puesta en escena de una "política de la materialidad" (Horton, 2006). Una dimensión que, a través de los juegos de reapropiación y reensamblaje, implicaba a la vez cuerpos y objetos excedentes, cables y carne. Lo político no sólo tenía cabida en reflexiones, en símbolos abiertos y despedazados, sino en la misma acción material y en la materia trabajada con las manos.

Lo que el taller nos recordaba, en todo su entusiasmo, en toda su fragilidad, es que la tecnología (y su reapropiación) es siempre, en cualquiera de sus contextos, una forma de ideología, un "hecho social total" -según la lógica maussiana-, simultáneamente material, social y simbólica (Pfaffenberger, 1988). Desde luego, su reapropiación o la negativa a asumir algunas de sus variantes también pueden darse en comunidades conservadoras; véase el ejemplo de los amish, quienes se niegan a la mecanización de su cotidianidad, amantes igualmente de la "autodependencia" y la "autogestión" (Hostetler, 1993). Toda tecnología "emerge de unas condiciones culturales particulares y de forma concomitante ayuda a producir otras" (Escobar, 2005: 15). No es ni buena ni mala, suele decirse, pero rara vez es neutral. Es precisamente la tradición de la modernidad la que ha creado una imagen neutral de la tecnología, ubicándola fuera de la sociedad, autónomamente. Nada tenía de neutral la planificación de Robert Moses de los pasos elevados de las autopistas. Nada de neutral las 
acciones de reciclaje y reensamblaje de nuestros protagonistas, ni su defensa de la bici como vehículo para la movilidad urbana.

\section{Conclusión: Abriendo la ciudad desde el cuerpo}

"Queremos a cidade chea de bicis, coma se fósemos civilizad@s". Llenar la ciudad de pedaleantes, tal era el objetivo último de ReCiclos. En esta frase uno encuentra ese punto "civilizado" con el que a menudo asociaban al vehículo; un artefacto, en el contexto europeo contemporáneo, con el que culminar el "proceso civilizatorio" (Elias, 1987), vehículo del ciudadano consciente, sostenible y responsable, pero también vehículo táctico, politizado desde los movimientos sociales para la lucha por la ciudad. Objeto flexible, simbólico, que en su circulación pone de manifiesto cómo el modo en que la gente se mueve refleja y genera problemas políticos y sociales, y cómo -a la vez- la gente performa las bicis tanto como éstas performan a la gente (Vivanco, 2013).

Frente al desparrame metropolitano de la ciudad, frente al vuelco hacia el exterior que hoy la define, las dos ruedas se presentan como un vehículo de recentramiento y redescubrimiento, a través del cual "recobrar la conciencia de sí mismos y de los lugares que habitan, invirtiendo el movimiento que proyecta a las ciudades fuera de sí mismas" (Augé, 2009: 63). Así, los itinerarios cicloactivistas o los paseos de la Masa Crítica, definida en algunos casos como "centro social en movimiento" (Lorenzi, 2010), no hacen sino invertir una tendencia histórica. En el siglo XIX, y hasta principios del XX, el velocípedo constituía para el feminismo y el socialismo un vehículo de expansión. Otorgaba a mujeres y trabajadores nuevos accesos a gentes y a lugares, expandiendo sus horizontes geográficos y políticos (Herlihy, 2004). Con él podían, por unas horas, dejar atrás la ciudad. Sin embargo, hoy se reclama como un artefacto para humanizar la escala urbana y relocalizar la vida cotidiana, no para huir de la ciudad sino para reconquistarla. Si feministas y socialistas lo usaban como medio para alcanzar los ritmos de la modernidad, hoy los cicloactivistas se echan a la calle para cuestionarlos. El mismo objeto, la misma tecnología móvil, es significada y reapropiada hoy con fines opuestos.

Para "hacer las ciudades más humanas", como decía Tomás, anteponían la sacralidad de las dos ruedas al carácter profano del coche, que amenazaba según ellos el ambiente y las relaciones. Fue su eclosión la que favoreció la urbanización expansiva, pues el sistema automovilístico estructuró a su alrededor no sólo un medio de transporte sino una forma de vida en la que el coche es más un nodo que una entidad independiente, vinculado a compañías de seguros, gasolineras, hoteles, áreas de servicio, parkings, centros comerciales, concesionarios, inmobiliarias, publicistas, urbanistas, etc. (Dennis; Urry, 2011). Una forma de vida en la que, durante mucho tiempo, el automóvil simbolizaba la integración en el pacto social, síntoma del ideal de movilidad social ascendente (López, 2012), "mensajero" y "objeto mágico" (Barthes, 2009), "cédula de ciudadanía" (Baudrillard, 1995) y "símbolo de poder" (Ward, 1996). Una ciudad orquestada en base a un modelo dominante de dependencia del coche, generado irónicamente por la independencia que supuestamente éste otorga al conductor, y que sin duda le otorga fuera de la ciudad y al tener que recorrer grandes distancias.

Al contrario que el coche, donde el conductor permanece atado y prácticamente inmóvil, y a diferencia del avión -paradigma del encierro y del cuerpo disciplinado, donde te desplazas en la medida en que no te mueves (Anta-Félez, 2013)-, la bici mantiene al cuerpo en contacto con el entorno, en público y a merced de los elementos, y la acción corporal es condición sine qua non para su funcionamiento. Así lo entendían y lo defendían mis informantes. Julio, por ejemplo, amante del cine, echaba mano de una técnica cinematográfica para describir su deslizamiento sobre dos ruedas por la ciudad: el travelling. En cada viaje decía redescubrir, rodando, el escenario urbano: "La bici te da otra visión", decía. El pedaleo, pues, como una forma de mirada; desacostumbrar al ojo, desfamiliarizar lo mirado 
para leer la ciudad de forma distinta. Frente al "encapsulamiento" del coche, comentaba, en sus paseos había algo de voyerismo. Aludía entones al flâneur baudeleriano, callejeador nato que miraba y a la vez participaba en el entorno. Por el contrario, la alta velocidad, la reducción del mundo a la ventanilla y la reducción del paisaje a pasaje, aminoran en el auto las opciones de diálogo con el entorno. Tal neutralización podría convertir a los conductores en telespectadores: "A diferencia del flâneur, el telespectador no transita para descubrir sino para evadir" (Ocampo, 2004: 93). En cambio, el velocípedo cobra entre los cicloactivistas el sentido de un vehículo relacional, un vehículo de percepción que funciona como extensión del cuerpo; tal y como otras tecnologías, actúa como prolongación del organismo, al igual que la computadora prolonga el cerebro, el teléfono la voz y la rueda las piernas (Hall, 1987). Un vehículo viejo y a la vez renovado, bueno para desafiar esa "crisis táctil" que atraviesa el individuo contemporáneo, en una era en la que el movimiento acelerado ha contribuido a privar al cuerpo de sensibilidad (Sennett, 1997), y en una época en la que el espacio se convierte en un derivado del movimiento, instrumentalista; un área de paso y no de permanencia.

Y así, al dejar ReCiclos y al pedalear entre coches, toda una ingeniería vital y de resistencia encontraba su traducción del taller al asfalto. Al igual que en el sótano se abría la tecnología, en la superficie se buscaba abrir la ciudad. En la Masa Crítica, por ejemplo, donde coincidían a menudo los mecánicos del taller, y que entre muchas de sus interpretaciones puede ser vista como la encarnación de una "conciencia rodante" que desnaturaliza y cuestiona la hegemonía del coche en el espacio público (Boal, 2012), y también como una "máquina de ritmos" (Diz, 2015), en tanto orquesta colectivamente un pedaleo rítmico ejercido sobre el tiempo de la calle, calmando el tráfico y recordando que, a través del espacio, "lo que se produce y reproduce es un tiempo social" (Lefebvre, 1976: 110), suponía -en palabras de Lois- una manera de hackear la ciudad. La Masa era, según él, una "táctica de estar

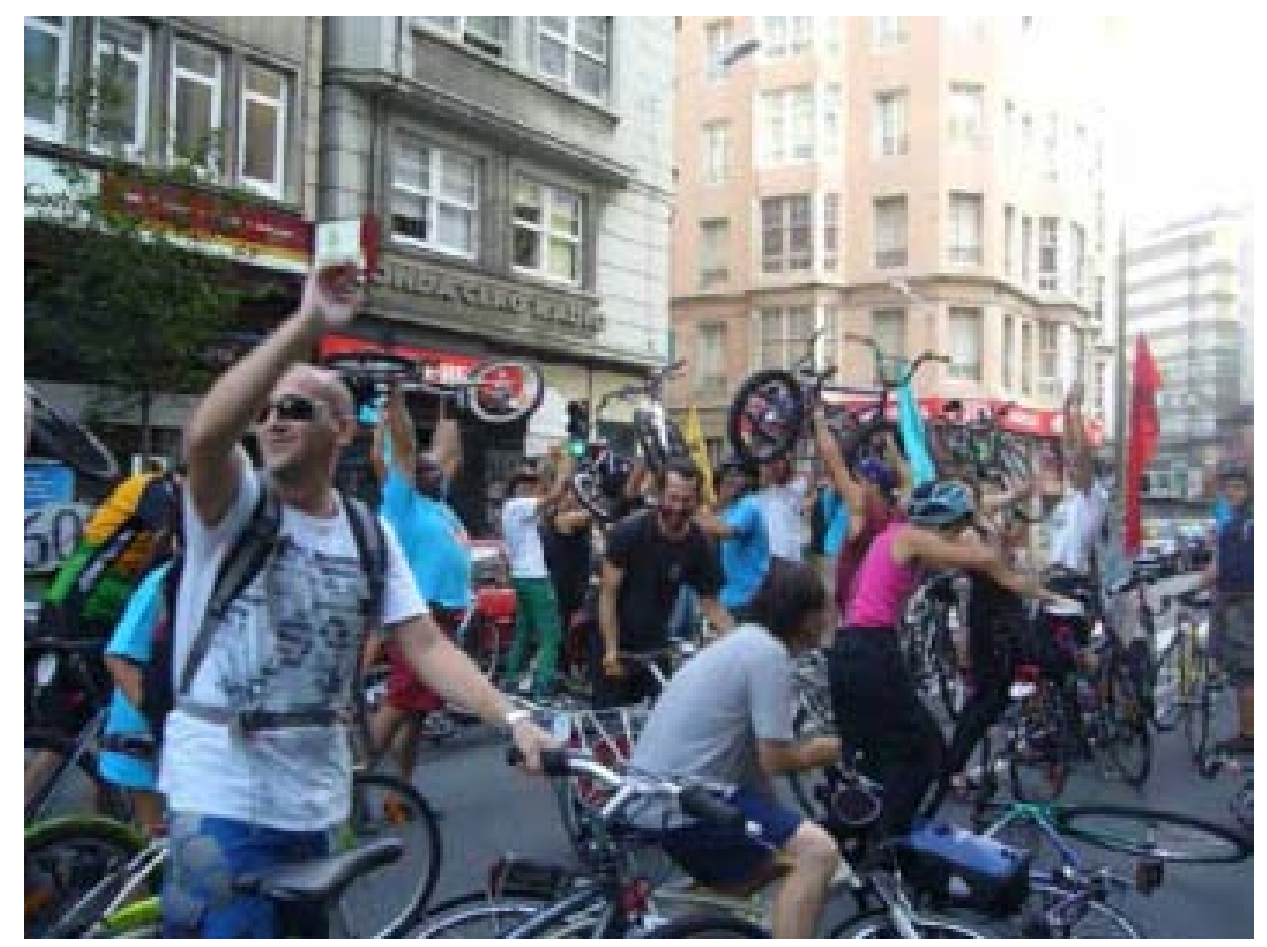

Figura 3. Masa Crítica. 
na rúa”, una manera de estar en el espacio, o mejor, una manera de hacer el espacio. Los "tapones" o "bloqueos" en las intersecciones, la entera ocupación de carriles, la conexión entre zonas distantes, el mantenimiento de la unidad, la flexibilidad en cuanto a los semáforos y a las demás normas de circulación, eran fórmulas con las que actuar dinámicamente sobre la ciudad y, durante un rato, transformarla.

Al igual que el activismo tecnosocial en ReCiclos funcionaba abriendo y maleando la tecnología, la Masa Crítica abría a su manera la ciudad en tanto materializaba y visibilizaba otras formas de recorrerla, y en tanto volvía transitable un espacio -y lo hacía, en su movimiento, habitable - para las dos ruedas y para la población ciclousuaria, habitualmente desplazada de las vías principales. La ciudad se hackeaba al intervenir en su materialidad, abriendo el acceso a calles y avenidas. Un derecho a la movilidad, por tanto, que pasaba en primera instancia (y a la vez) por un derecho a participar y a decidir sobre las cuestiones tecnológicas y sobre las cuestiones urbanas. Si las infraestructuras metropolitanas también pueden ser hoy comprendidas en tanto "ensamblajes urbanos" (Farias; Bender, 2009), conjunción de relieves, materias, ideas, paisajes, prácticas, discursos y representaciones, el actual cambio de paradigma, la transición mitológica contemporánea que sitúa a la bicicleta en el centro de las nuevas movilidades, debe reconocer y dar pie a los sucesivos procesos de reapropiación y reensamblaje, asumiendo -tal y como lo hacen nuestros protagonistas- la intrínseca relación entre lo material y lo social, entre lo urbano, lo político y lo tecnológico. Tal y como ocurría en el taller y después en las calles, llenar la ciudad de cosas equivalía a llenar de cosas la política.

\section{Bibliografía}

AMAR, George

2011 Homo Mobilis. La nueva era de la Movilidad. Buenos Aires: La Crucija.

ANTA-FÉLEZ, José L.

2013 "Una etnografia del avión. Cuerpos sujetos a la disciplina del consumo viajero", en AIBR, VIII, 3: 323-344.

APPADURAI, Arjun

1986 "Introduction: commodities and the politics of value", en Appadurai, A. (Edit.). The social life of things: 3-63. Cambridge University Press.

2000 "Grassroots globalization and the research imagination", en Public Culture, XII, 1: 1-19.

AUGÉ, Marc

2009 Elogio de la Bicicleta. Barcelona: Gedisa.

BACHELARD, Gaston

$2000 \quad$ La Poética del Espacio. México: FCE.

BARTHES, Roland

2009 Mitologías. Madrid: Siglo XXI.

BAUDRILLARD, Jean

1995 El Sistema de los Objetos. Madrid: Siglo XXI.

2012 La Sociedad de Consumo. Madrid: Siglo XXI.

BOAL, Iain A.

2012 "CM@20: revolution in the street”, en Carlsson, C.; Elliot, L.; Camarena, A. (Edits.). Shift happens! Critical Mass at 20: 316-320. San Francisco: Full Enjoyment Books.

CASTELLS, Manuel

1995 La ciudad Informacional. Madrid: Alianza.

2004 La cuestión Urbana. México: Siglo XXI.

DE GIORGI, Alessandro

2006 El Gobierno de la Excedencia. Madrid: Traficantes de Sueños.

DENNIS, Kingsley; URRY, John

2011 Un mundo sin coches. Barcelona: Península. 
DIZ, Carlos

2015 Políticas y Tácticas del cuerpo: Retablos de la ciudad Activista. A Coruña: Universidade da Coruña [Tesis doctoral].

DOUGLAS, Mary

1998 Estilos de pensar. Barcelona: Gedisa.

ELIAS, Norbert

1987 El Proceso de Civilización. Madrid: FCE.

ELLIOT, Anthony; URRY, John

2010 Mobile Lives. Londres: Routledge.

ESCOBAR, Arturo

2005 "Bienvenidos a Cyberia. Notas para una antropología de la cibercultura", en Revista de Estudios Sociales, XXII: 15-35.

ESTALELLA, Adolfo

2012 "Ensamblajes de esperanza. Una etnografia del bloguear apasionado", en Athenea Digital, II: $161-174$.

FARIAS, Ignacio; BENDER, Thomas (Edits.)

2009 Urban Assemblages. How actor-network Theory changes urban Studies. Londres: Routledge.

FERNÁNDEZ DURÁN, Ramón

1980 Transporte, Espacio y Capital. Madrid: Nuestra Cultura.

FURNESS, Zack M.

2006 'Put the fun between your Legs. The Politics and Counterculture of the Bicycle. Pittsburgh: Universidad de Pittsburgh [Tesis doctoral].

GIDDENS, Anthony

1993 Consecuencias de la Modernidad. Madrid: Alianza.

GIUCCI, Guillermo

2007 La vida Cultural del Automóvil. Buenos Aires: Universidad Nacional de Quilmes.

GRAHAM, Stephen; MARVIN, Simon

2001 Splintering Urbanism: Networked Infrastructures, Technological Mobilities and the ur-

HALL, Edward T. ban Condition. Londres: Routledge.

1987 La Dimensión Oculta. Madrid: Siglo XXI.

HARVEY, David

1979 Urbanismo y Desigualdad social. Madrid: Siglo XXI.

2008 La Condición de la Posmodernidad. Buenos Aires: Amorrortu.

HERLIHY, David

2004 Bicycle. The History. New Haven: Yale University Press.

HIMANEN, Pekka

2002 La Ética hacker y el Espíritu de la era de la Información. Barcelona: Destino.

HORTON, Dave

2006 "Environmentalism and the bicycle", en Environmental Politics, XV, 1: 41-58.

2009 "Social movements and the bicycle", en http://thinkingaboutcycling.com/socialmovements-and-the-bicycle/ (04/06/2013)

HOSTETLER, John

1993 Amish Society. Baltimore: The John Hopkins University Press.

JURIS, Jeffrey S.

2008 Networking Futures. Durham: Duke University Press.

KOPYTOFF, Igor

1986 "The cultural biography of things: commoditization as process", en Appadurai, A. (Edit.). The social life of things: 64-92. Cambridge University Press.

LATOUR, Bruno

2008 Reensamblar lo social. Buenos Aires: Manantial.

LATOUR, Bruno; GAGLIARDI, Pasquale (Directs.)

2008 Las Atmósferas de la Política. Madrid: Complutense. 


\section{LEFEBVRE, Henri}

1976 Espacio y Política. El Derecho a la ciudad, I. Barcelona: Península.

2013 La Producción del Espacio. Madrid: Capitán Swing.

LÉVI-STRAUSS, Claude

1992 El Pensamiento Salvaje. México: FCE.

LÓPEZ, Isidro

2012 “Cuántas utopías y distopías caben en un coche?”, en Diagonal. https://www.diagonalperiodico.net/especiales/cuantas-utopias-y-distopias-caben-coche.html (23/05/12).

LORENZI, Elizabeth

2010 "Centro social en movimiento. Los talleres de auto-reparación de bicicletas en espacios autogestionados", en Domínguez, M; Martínez, M; Lorenzi, E. Okupaciones en Movimiento: 133-185. Madrid: Tierra de nadie.

MARCUS, George E.

2001 "Etnografía en/del Sistema mundo. El surgimiento de la etnografía multilocal", en Alteridades, XI, 22: 111-127.

McCRACKEN, Grant

1986 "Culture and consumption: a theoretical account of the structure and cultural meaning of consumer goods", en Journal of Consumer Research, XIII, 1: 71-84.

MENDOZA, Edith

2016 "El papel de los ciclistas y la bicicleta en el urbanismo sostenible", en Contested Cities. http://contested-cities.net/CCmadrid/2020-2/ (09-02-2016).

MUMFORD, Lewis

2006 "Técnicas autoritarias y técnicas democráticas", en Riechmann, J. (Or.). Perdurar en un Planeta Habitable: 185-196. Barcelona: Icaria.

OCAMPO, Pablo

2004 "Periferia. La heterotopía del no-lugar", en Urbano, VII, 9: 92-95.

PFAFFENBERGER, Bryan

1988 "Fetishized objects and humanized nature: towards an anthropology of technology", en Man, 23: 236-252.

ROSEN, Paul

2002 "Up the Vélorrution: appropriating the bicycle and the politics of technology", en Bleecker, J.; Croissant, J.; Di Chiro, G.; Eglash, R.; Fouché, R. (Edits.). Appropriating Technology: 365-391. Mineápolis: University of Minnesota Press.

SADOWSKI, Jathan; PASQUALE, Frank

2015 "The spectrum of control: a social theory of the smart city", en First Monday. http://journals.uic.edu/ojs/index.php/fm/article/view/5903/4660 (06-07-2015).

SASSEN, Saskia

1999 La ciudad global. Buenos Aires: Eudeba.

SENNETT, Richard

1997 Carne y piedra. Madrid: Alianza.

SLOTERDIJK, Peter

2006 Esferas III. Espumas. Madrid: Siruela.

SOJA, Edward

2008 Postmetrópolis. Madrid: Traficantes de Sueños.

TIRONI, Martín

2015 "(De)politicising and ecologising bicycles. The history of the parisian Vélib' system and its controversies", en Journal of Cultural Economy, VIII, 2: 166-183.

VELASCO, Honorio M.

2010 "Los procesos de construcción y deconstrucción del cuerpo en perspectiva antropológica", en Martínez Guirao, J.; Téllez Infantes, A. (Edits.). Cuerpo y Cultura: 19-54. Barcelona: Icaria.

VERA, Paula

2013 "Imaginarios tecnológicos y procesos de construcción urbana en la ciudad moderna. El ferrocarril, el automóvil y las TIC", en URBS. Revista de Estudios Urbanos y ciencias Sociales, III, 1: 9-26. 
VIVANCO, Luis

2013 Reconsidering the Bicycle: An Anthropological Perspective on a new (old) thing. Nueva WARD, Colin York: Routledge.

1996 Contra el Automóvil. Barcelona: Virus.

WILLIAMS, Raymond

2011 El campo y la ciudad. Buenos Aires: Paidós.

WINNER, Langdon

1980 "Do artifacts have politics?", en Daedalus, CIX, 1: 121-136.

\section{3}

